\title{
Analyse économique du droit
}

Introduction

\section{Pierre Ralle}

\section{(2) OpenEdition}

\section{Journals}

Édition électronique

URL : http://journals.openedition.org/travailemploi/3662

DOI : $10.4000 /$ travailemploi.3662

ISSN : 1775-416X

Éditeur

DARES - Ministère du Travail

Édition imprimée

Date de publication : 15 décembre 2009

Pagination : 7-8

ISSN : 0224-4365

\section{Référence électronique}

Pierre Ralle, «Analyse économique du droit », Travail et Emploi [En ligne], 120 | octobre-décembre 2009, mis en ligne le 30 décembre 2011, consulté le 22 septembre 2020. URL : http://

journals.openedition.org/travailemploi/3662 ; DOI : https://doi.org/10.4000/travailemploi.3662 


\section{Dossier Analyse économique du droit}

\section{Introduction}

En 2005, la Direction de l'animation de la recherche, des études et des statistiques (DARES) et la Direction des Relations du Travail (DRT) ont lancé un appel à projets de recherche sur le thème de «L'analyse économique du droit du travail»(1), dont les trois articles qui composent ce dossier sont issus. Cet appel à projets se donnait pour finalité d'apporter un éclairage sur l'impact réel du droit du travail, en apportant des éléments sur son efficacité, son effectivité et son efficience. L'éclairage attendu devait permettre de mieux apprécier la performance à la fois économique et sociétale du régime juridique français, de son mode de production à celui de sa mise en œuvre. La démarche évaluative et pluridisciplinaire, devait analyser les évolutions des conditions de production de l'offre juridique et les attentes des acteurs, ainsi que la manière dont ils se saisissent des instruments mis à leur disposition.

Quatre grands types de question étaient posés:

- l'articulation du droit du travail avec les autres droits;

- les transformations de la façon dont s'élabore le droit du travail;

- l'appréciation de la complexité du droit français ainsi que le niveau réel de connaissance de la législation du travail par les différents acteurs;

- enfin, les éventuels obstacles à la création d'emplois engendrés par le droit du travail.

Deux offres ont été sélectionnées dans le cadre de cet appel à projets de recherche.

Une première recherche, "Analyse économique du droit du travail », a été réalisée par l'université Nancy 2 (2), sous la direction de Cécile Bourreau-Dubois et Bruno Deffains. La seconde «L'évaluation du droit du travail : problèmes et méthodes ", a été réalisée par l'Institut international pour les études comparatives (3) sous la direction d'Antoine Lyon-Caen et de Joëlle Affichard.

Les deux premiers articles du dossier : « Economie et droit du travail : des discours récurrents mais non rivaux » de Cécile Bourreau-Dubois et Bruno Deffains et «Les absences au travail en Europe : quel impact du régime d'indemnisation maladie et de la législation de protection de l'emploi sur les comportements des salariés ? » de Sabine Chapain-Guillot et Olivier Guillot sont issus de la première recherche. L'article de Raphaël Dalmasso et Thierry Kirat intitulé « Comparer, mesurer, classer: 1'art périlleux de la leximétrie du licenciement » est issu de la seconde.

La thèse principale défendue dans : «Économie et droit du travail : des discours récurrents mais non rivaux» est que l'économie du droit est une voie pertinente (même si les auteurs soulignent qu'elle n'est pas unique) pour "établir un dialogue" entre approche économique et approche juridique du droit du travail. Cette thèse est illustrée à partir de l'analyse de l'évolution des licenciements économiques et des licenciements pour motif personnel et de l'hypothèse de "substitution". Les conclusions de ce papier ne relèvent pas uniquement du registre de la théorie, puisque les auteurs prônent

(1) L'appel d'offres DARES / DRT peut être consulté sur le site du ministère du travail http://www.travail-solidarite.gouv.fr/etudesrecherche-statistiques-dares/etudes-recherche/ rubrique : appels projets passés.

(2) Le rapport peut être consulté sur le site http://cournot2.u-strasbourg.fr/users/beta/ rubrique Dossier Dares

(3) Synthèse du rapport consultable sur le site http://www.iipec.eu/site/sites/default/files/evaluationdw_vol1_1.pdf 
l'évolution de la statistique publique, afin qu'elle permette une meilleure analyse économique des contentieux de travail.

C'est justement un travail statistique approfondi que présente « Les absences au travail en Europe : quel impact du régime d'indemnisation maladie et de la législation de protection de l'emploi sur les comportements des salariés?». À partir d'un panel européen des ménages observés en 1996 et 2001, les auteurs étudient les absences au travail en Europe. La générosité de l'indemnisation de la maladie semble favoriser les absences au travail (en 2001 mais en pas 1996 et il sera intéressant de savoir si cette évolution est liée à une conjoncture différente ou à des modifications structurelles ou encore à des problèmes de mesure statistique). Quant au degré de protection de l'emploi, il semble jouer un rôle inattendu (défavorable aux absences au travail), les auteurs questionnant finalement l'influence théorique de l'indicateur comme la pertinence de sa mesure.

C'est aussi de mesure qu'il question dans «Comparer, mesurer, classer: l'art périlleux de la leximétrie du licenciement». L'article discute des comparaisons internationales des indicateurs de protection de l'emploi. La thèse défendue par les auteurs est que ce ne sont pas tant les règles de droit qui doivent être comparées d'un pays à l'autre mais les procédures car le «mode d'existence des règles passe par les procédures et leur administration». Le jugement porté sur les classements internationaux fondés sur les mesures de la réglementation est alors sévère (les auteurs expriment justement leurs «réserves»). En particulier parce qu'ils éludent la variété internationale des procédures de licenciement et la diversité des formes de présence du droit dans les entreprises.

Au total, sur un sujet au moins aussi important en 2010 qu'en 2005, ce dossier est d'une lecture stimulante.

Pierre Ralle 